\title{
High Speed Operation Design Considerations For Fractional Slot Axial Flux PMSM
}

\author{
A. Hemeida, M. Taha, and P. Sergeant,
}

\begin{abstract}
This paper discusses intensively the design considerations for the fractional slot axial flux permanent magnet synchronous (AFPMSMs) in order to work efficiently in the constant power speed range, also known as the field weakening (FW) region. The dominant parameter in the constant power speed region is called the characteristic current which equals the ratio of the magnet flux linkage over the synchronous inductance $\left(-\psi_{m} / L_{S}\right)$. Several machine parameters is affecting the characteristic current including the machine geometry and the winding configurations. In this paper, the effect of many of these parameters on the FW has been discussed; including the outer diameter, inner to outer diameter ratio, magnet size, slot opening width, slots per poles combinations, and the multi phase configurations for the Axial flux permanent magnet synchronous machine (PMSM). Two main governors are considered to evaluate the parameters' impact on the machine overall performance; the rated machine efficiency and the torque to weight ratio at the highest values. Selection of these governors is application driven where these governors are the most influencing factors on the axial flux PMSM design. The results of the present analysis show that the fine tuning of the discussed machine parameters would derive the motor to work in the required Constant Power Speed Region (CPSR) keeping the required high efficiency and torque to weight ratio. A previously proved analytical model has been used in this study to overcome the highly time consumption in the finite element model (FEM).
\end{abstract}

Keywords-AFPMSM, Concentrated winding, CPSR, Field Weakening, Fractional slot winding, High Speed Operation,

\section{INTRODUCTION}

A Xial flux permanent magnet synchronous machines (AFPMSMs) are one of the best choices in several applications, such as the hybrid electric vehicles [1] and wind generators [2]. There are several types of the AFPMSM's [3]. Thanks to the absence of the yoke in the machine, the yokeless and segmented armature machine (YASA) shown in Fig. 1 has a very high efficiency and torque density. These advantages support this type of motors to be the most selective machines over several types for such applications [3].

Working in a wide constant power speed region (CPSR) is highly required for many applications especially the electric vehicle as well as the wind energy applications [3] - [6] . CPSR ratio is usually used to define the ratio between the targeted high speed to the rated speed, this ratio is application dependant. The CPSR ratio varies from (2:1) [7] up to (10:1)

A. Hemeida, M. Taha, and P. Sergeant are with the Department of Electrical Energy, Systems and Automation, Ghent University, Belgium. (e-mail: a.hemeida@ieee.org; mohamd.taha@cu.edu.eg,p.sergeant@ugent.be).

M. Taha is also with the Electrical Power and Machines Department, Cairo University, 12613 Giza, Egypt. in some literatures like [8], [9] and may be even higher. The optimal flux weakening characteristic can be achieved by the synchronous reluctance motors, surface PMSM (SPMSM) or Interior PMSM (IPMSM) [10]. The Axial Flux Permanent Magnet Synchronous Machine (AFPMSM) shown in Fig. 1 is considered as a surface mounted Permanent Magnet Synchronous Machines. [11], [12]

The analysis of the surface PMSM in the CPSR has been done in several literatures [10], [13] [14] [15]. Analysis of the PMSM has concluded that assuring that the characteristic current $\left(I_{c}=\left(-\frac{\psi_{m}}{L_{s}}\right)\right.$ is lower than the rated current should guarantee a "theoretical" infinite CPSR. This ratio is quite dependant on the machine parameters like the inner diameter, the outer diameter, the slot opening, and the magnet size. To perform this study, a fast and an accurate appealing results were needed. Analytical models developed in [16]-[18] are capable of obtaining the complete machine parameters in an accurate and fast way. These parameters include the terminal voltage, torque, PM losses, stator core losses and inductances. These models are verified against the FE model. This model is used to check the selected parameters' impact on the characteristic current. For the sake of comparison, the machine's rated power, speed and torque are constant in all cases.

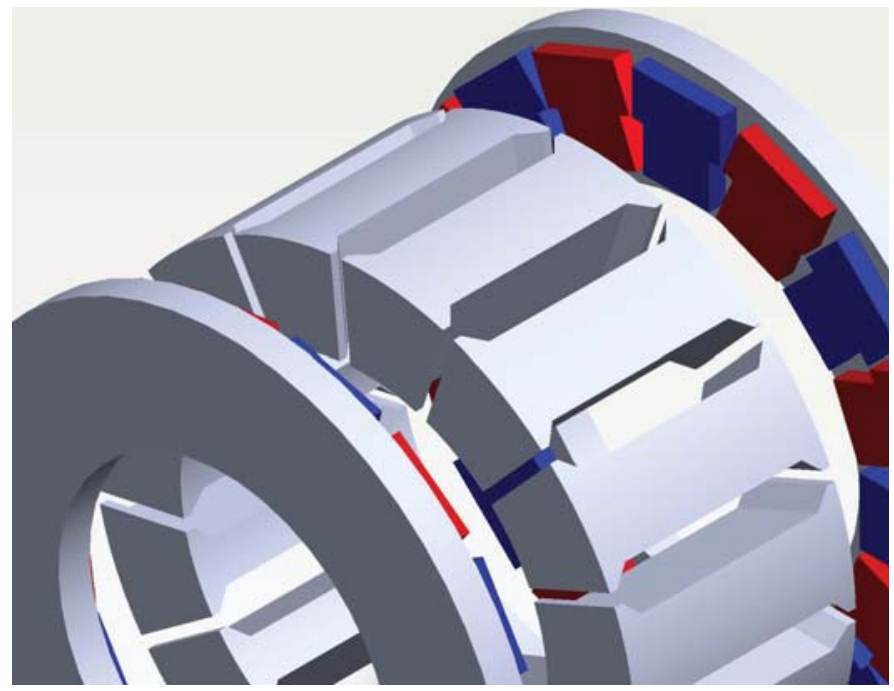

Fig. 1: Axial Flux PMSM.

This paper will be organized as follows; first section will discuss the basic equations for the CPSR operation in the AFPMSM, in this section the key factors during the FW operation will be highlighted to be discussed in the remaining sections. 
Second section to discuss the basics of the analytical model to be used for the motor parameter analysis and design procedure. The remaining sections will discuss the impact of each selected machine's parameter on the key factors highlighted in section II.

\section{AXIAL FLUX PMSM SIMPLIFIED MODEL}

In [14], the SPMS motor lossless equations are shown, these equations could be used for the axial PMSM as described below;

$$
\begin{gathered}
V_{d}=-\omega L_{s} I_{q} \\
V_{q}=-\omega L_{s} I_{d}+\omega \psi_{m} \\
T=\left(\frac{3}{2}\right) \rho \psi_{m} I_{q}
\end{gathered}
$$

The machine's voltage and current limits could be described by the following equations;

$$
\begin{gathered}
I_{r}^{2}=I_{d}^{2}+I_{q}^{2} \\
V_{r}^{2}=V_{d}^{2}+V_{q}^{2} \\
V_{r}^{2}=\left(\omega L_{s} I_{q}\right)^{2}+\left(\omega L_{s} I_{d}+\omega \psi_{m}\right)^{2} \\
\frac{V_{r}^{2}}{\left(\omega L_{s}\right)^{2}}=\left(I_{q}\right)^{2}+\left(I_{d}+\frac{\psi_{m}}{L_{s}}\right)^{2}
\end{gathered}
$$

Where; $V_{d}$ and $V_{q}$ are the direct and quadrature voltage components respectively, $I_{d}$ and $I_{q}$ are the direct and quadrature current components respectively , $V_{r}$ and $I_{r}$ are the machine's rated current and voltage respectively. $\omega$ is the electrical angular speed.$\rho$ is the number of pole pairs. $\psi_{m}$ is the permanent magnet flux linkage . $\mathrm{T}$ is the electromechanical torque.

Drawing (4) in the d-q plan will represent a circle centered at the origin with a radius equals to the rated current. To represent the voltage limits over the same graph, substituting from (1) and (2) in (5) will result in (6). (6) could be reformatted as shown in (7) which represents another circle but centered at $\left(-\frac{\psi_{m}}{L_{s}}\right)$ with radius of $\frac{V_{r}}{\left(\omega L_{s}\right)}$. It is obvious that increasing the speed will decrease the radius of the voltage circle. Figure 2 and 3 show the voltage and current limits in the d-q plan at different speeds. The key parameter here is the characteristic current. Figure 2 shows the infinite CPSR, where the $I_{c}<I_{r}$, on the other hand Fig. 3 shows the finite CPSR where $I_{c}>I_{r}$. In case of the finite CPSR, the maximum speed $\left(n_{m}\right)$ that could be reached by the field weakening is shown in Fig.3, at which the voltage circle radius is $\left(\left(\frac{\psi_{m}}{L_{s}}-I_{r}\right)\right)$.

From the above discussion, it can be concluded that the characteristic current is the key parameter to determine the machine capability to work in the FW region.

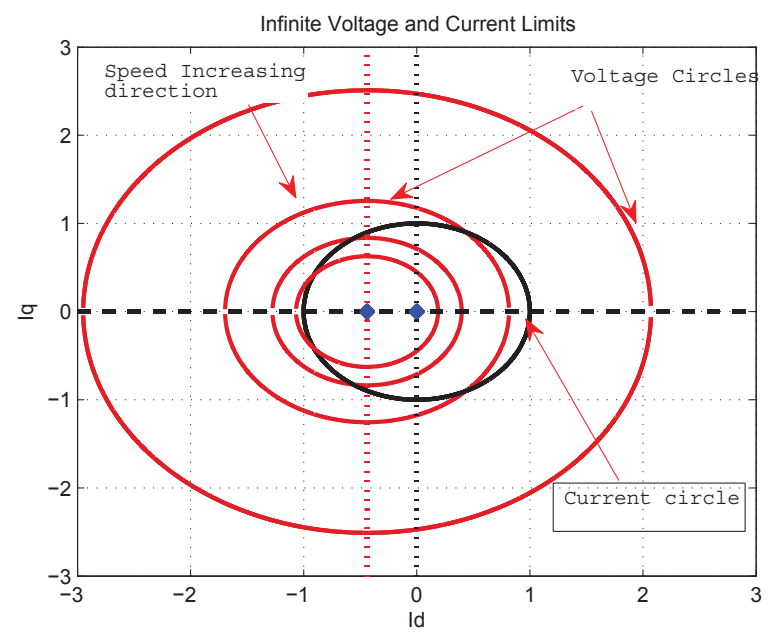

Fig. 2: Infinite CPSR.

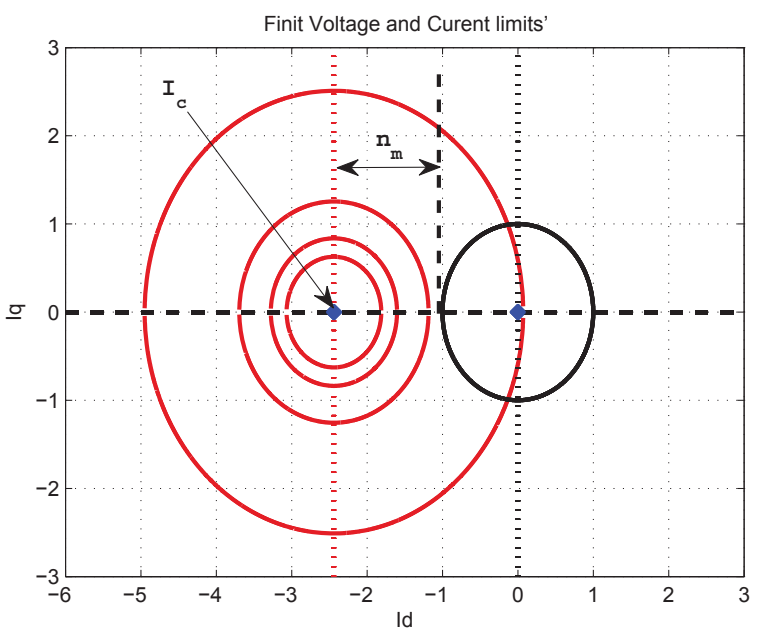

Fig. 3: Finite CPSR.

\section{ANALyticAl Model}

In [16], [17], the developed circuit model is capable of obtaining several machine parameters and it has been proved that this model would be a better choice for a fast design tool for the AFPMSM due to the fast appealing results of the model within a very good accuracy compared to the FE results.

This model is based on a combined solution of Maxwell's equations and Magnetic Equivalent Circuit (MEC). Maxwell's equations are used to solve the magnetic flux density in the air gap area. Stretching the machine to the 2D has been used assuming each layer thickness is $t_{c p}$. The developed Maxwell's equations are based on assuming infinite permeability core in the material.

Three sources are used to model the machine. Firstly, the permanent magnet $(\mathrm{PM})$ axial $\left(B_{y I I_{p m}}\right)$ and circumferential $\left(B_{x I I_{p m}}\right)$ magnetic flux density are obtained. Then the magnetic flux density for the current distribution $\left(B_{x I I_{c}}\right)$ and $\left(B_{y I I_{c}}\right)$ in the space for fractional slot concentrated windings are ob- 
tained accordingly. Finally, the slotting effect is included using Schwarz-Christoffel transformation described in [19].

These source fields are used afterwards to excite the magnetic equivalent circuit described in [16]. The result of this analytical model includes the magnetic saturation in the iron core described by the MEC. It was shown in this paper that the accuracy obtained in the calculation of core losses, torque and terminal voltage is highly motivated compared to the time consumed by the FE models.

Another circuit model described in [17] is used to solve the eddy currents flowing through the PM's. The idea behind this model is also based firstly on obtaining the flux density solution on the volume of the PM. These flux densities are reconstructed on the complete volume of the PM. In a consequence, these values are used to excite the resistance network that is capable of estimating the eddy currents on many slices in the axial direction of the PM. Finally, the PM losses are obtained accordingly.

The main advantage of the analytical model that it is geometrical independent. The parameters can be changed in an easily way and the solution could be obtained afterwards in a fast way. It is also possible to change the number of slots and poles combinations for any value with any number of phases.

The number of slots and poles combinations are chosen to avoid the un-symmetry in the mechanical distribution of slots in space to avoid the magnetic pull force. This is more demonstrated in [20], [21].

The basic design concept is based on obtaining a certain combination for the slots and poles for certain number of phases for a certain outer diameter. This outer diameter is obtained initially according to [22]. It was proven mathematically that the optimum inner to outer diameter ratio is $65 \%$. This value could be changed slightly to achieve the optimum design. The PM axial length and width is determined according to the air gap flux density required in the space. The Number of turns are assumed to be unity and a current of one amp's is injected in the model including maxwell's equations and MEC. Then the voltage at no load is anticipated for one turn and according to the required phase voltage, the number of turns are determined. The required power determines the amapacity of the machine. The tooth width is determined according to the required flux density inside the stator teeth. The slot axial length is calculated based on a maximum current density of $\left(2 \mathrm{~A} / \mathrm{mm}^{2}\right)$ in the slots.

Table I shows the initial parameters for the $5 \mathrm{KW}$ machine, these parameters are not fulfilling the required CPSR ratio of 5. The current ratio of the machine is 1.3. Last column shows the testing values used in this study to change the FW capability of this machine.

\section{OUter Diameter IMPACT}

In Fig. 4.a, the intersection point between $I_{c}$ and $I_{r}$ creates a vertical line that segregates between the finite and the infinite region. It is quite clear that working with infinite CPSR for this machine would result in a lower efficiency at the rated operating point. Accordingly, to keep the highest efficiency with the field weakening capability, the finite CPSR should be selected in this case. As a consequence, the maximum reachable speed should fulfill the application requirements from the speed and efficiency point of view. As an example, the selected maximum speed is chosen as five times the rated speed $\left(n_{m}=2500 * 5=12500 \mathrm{rpm}\right)$. This would result in an efficiency of $95 \%$ at rated speed and an outer diameter of $1.25 \mathrm{~mm}$ as shown in Fig. 4 a. From Fig. 4 b, the impact on the torque density has slightly changed due to the reduction of the total axial length of the machine. As a conclusion, keeping higher efficiency would require a certain CPSR limit. A CPSR ratio of five is selected in this case as an example. In order to Reach a value greater than 5, the outer diameter should be chosen smaller to keep the permanent magnet flux value lesser. In consequence, the required number of turns will increase and the total cupper losses will dramatically increase reducing the total efficiency of the system.

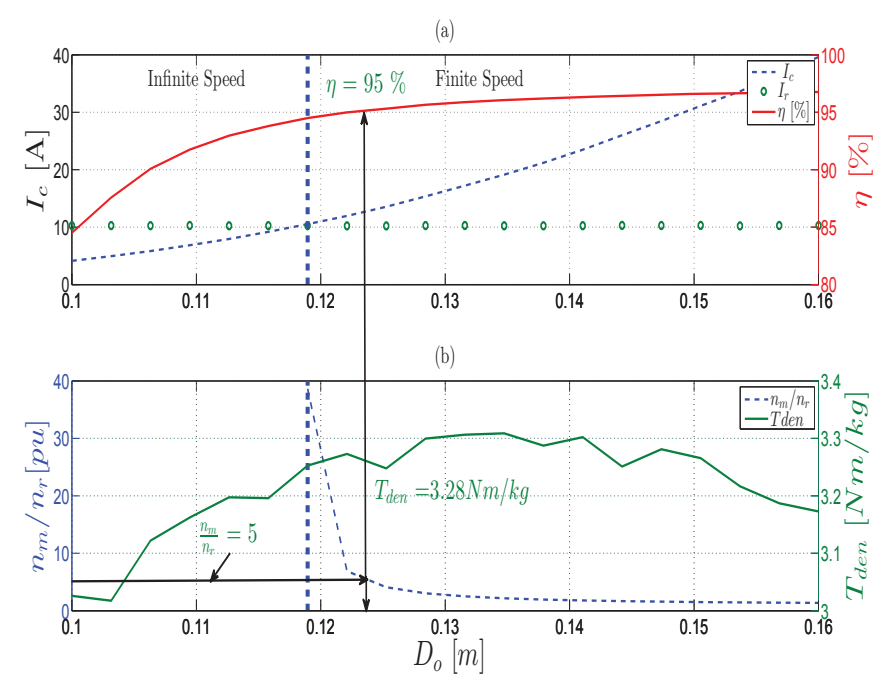

Fig. 4: Outer Diameter Impact (a) Do versus $I_{c}, I_{r}$, and the $\eta$ (b) Do versus the torque to weight ratio, and the Per unit speed $\frac{n_{m}}{n_{r}}$.

TABLE I: Geometrical and electromagnetic parameters of the studied machine.

\begin{tabular}{l|ccc}
\hline \hline Parameters & Symbol & Value & Testing ranges - values \\
\hline Number of pole pairs & $p$ & 8 & Different combinations \\
\hline Number of stator slots & $Q_{s}$ & 15 & Different combinations \\
\hline Rated speed & $\Omega$ & $2500 \mathrm{rpm}$ & $2500 \mathrm{rpm}$ \\
\hline Rated Torque & $T_{e m}$ & $19 \mathrm{~N} . \mathrm{m}$ & $19 \mathrm{~N} . \mathrm{m}$ \\
\hline Rated Voltage & $V$ & $230 \mathrm{~V}$ & $230 \mathrm{~V}$ \\
\hline $\begin{array}{l}\text { Remanent flux density } \\
\text { of the PM }\end{array}$ & $B_{r}$ & $1.26 \mathrm{~T}$ & $1.26 \mathrm{~T}$ \\
\hline Outer diameter $\left(D_{o}\right)$ & $D_{o}$ & $148 \mathrm{~mm}$ & $100-160 \mathrm{~mm}$ \\
\hline Inner diameter & $D_{i}$ & $100 \mathrm{~mm}$ & $(0.6-0.85) D_{o}$ \\
\hline Axial length core element & $Y_{s}$ & $60 \mathrm{~mm}$ & Design output \\
\hline Slot width $t_{s}$ & $t_{s}$ & $11 \mathrm{~mm}$ & Design output \\
\hline Slot opening width & $t_{s o}$ & $3 \mathrm{~mm}$ & $(0.1-0.6) t_{s}$ \\
\hline Axial thickness magnet & $Y_{m}$ & $5 \mathrm{~mm}$ & $5 \mathrm{~mm}$ \\
\hline Air gap axial length & $g$ & $1 \mathrm{~mm}$ & $1 \mathrm{~mm}$ \\
\hline
\end{tabular}




\section{INNER TO OUTER DiAMETER IMPACT}

Same as the previous section, in Fig. 5 a the intersection point between $I_{c}$ and $I_{r}$ creates a vertical line that segregates between the finite and the infinite region. However, in this case the finite CPSR is located on the left side from the intersection line. This means that increasing the inner to outer diameter ratio would enhance the CPSR capabilities. On the other hand, the efficiency would get worse. Similar to the previous case; the impact on the torque to weight ratio could get worse as shown in Fig. $5 \mathrm{~b}$ as the inner to outer diameter ratio get increased. The inner to outer diameter ratio would reduce the PM flux linkage and in consequence the total number of turns would increase to keep the same torque value.

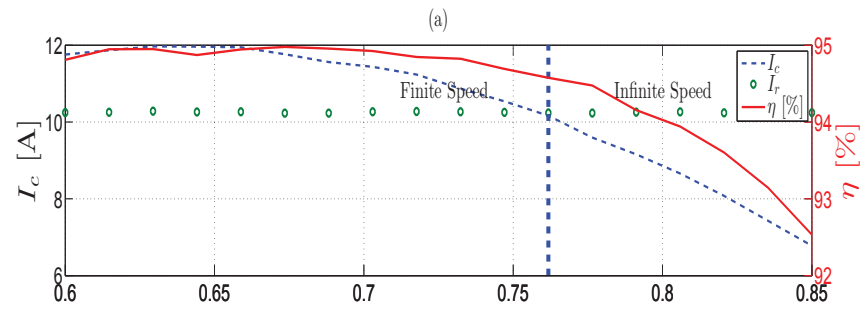

(b)

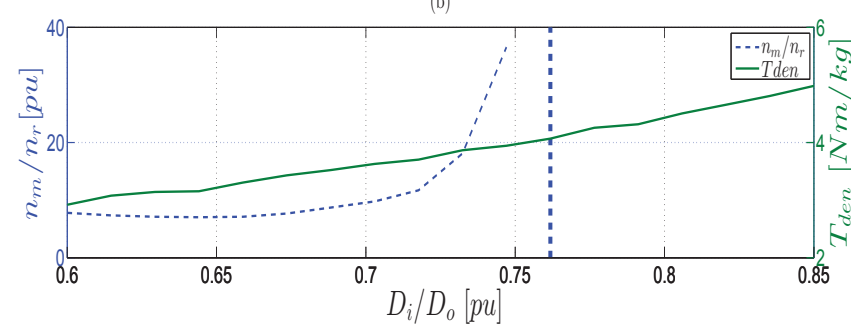

Fig. 5: $\frac{D_{i}}{D_{o}}$ Impact (a) $D_{i} / D_{o}$ versus $I_{c}, I_{r}$, and the $\eta$ (b) $D_{i} / D_{o}$ versus the torque to weight ration, and the Per unit speed $\frac{n_{m}}{n_{r}}$.

\section{SLOT OPENING IMPACT}

Figure. $6 \mathrm{a}$ and $\mathrm{b}$, shows the impact of changing the slot opening width in working in the the CPSR . It could be drawn that increasing the slot opening would reduce the leakage flux and in consequence, the inductance would reduce too. This reduces the maximum reachable speed. The efficiency and torque density values are slightly affected by the change. This would conclude that achieving the infinite CPSR based on changing the slot opening is quite difficult in this case, on the other hand the finite CPSR could be selected based on the required efficiency.

\section{MAGNET WIDTH IMPACT}

Figure 7. $\mathrm{a}$ and $\mathrm{b}$ show the impact of changing the PM width on the maximum speed ratio, efficiency and torque density. It is quite clear that magnet width increasing would result in a higher efficiency and lower CPSR ratio. This would conclude that changing the magnet width could be sufficient in case of working in the finite CPSR.

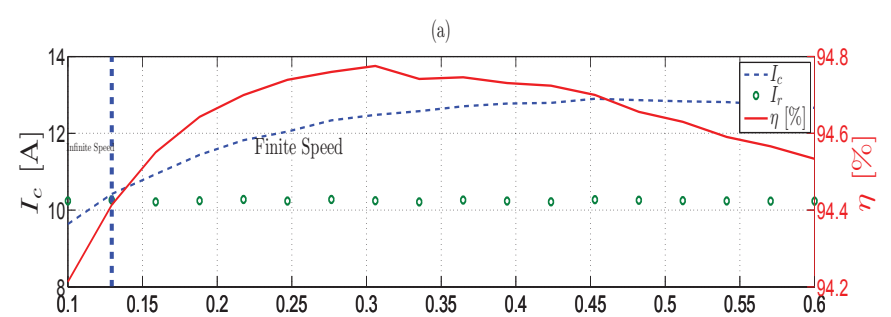

(b)

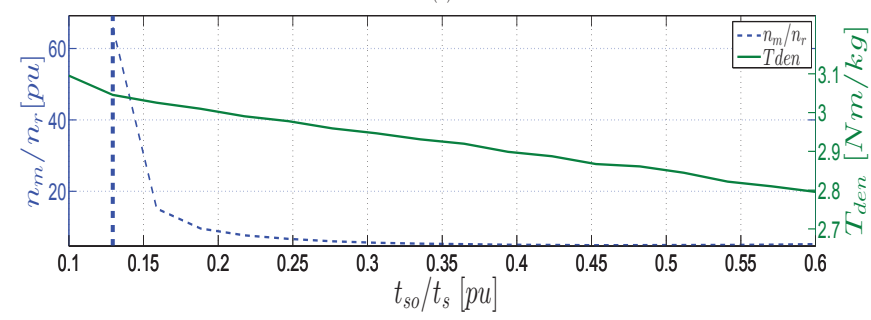

Fig. 6: Slot opening Impact (a) $t_{s o} / t_{s}$ versus $I_{c}, I_{r}$, and the $\eta$ (b) $t_{s o} / t_{s}$ versus the torque to weight ration, and the Per unit speed $\frac{n_{m}}{n_{r}}$.
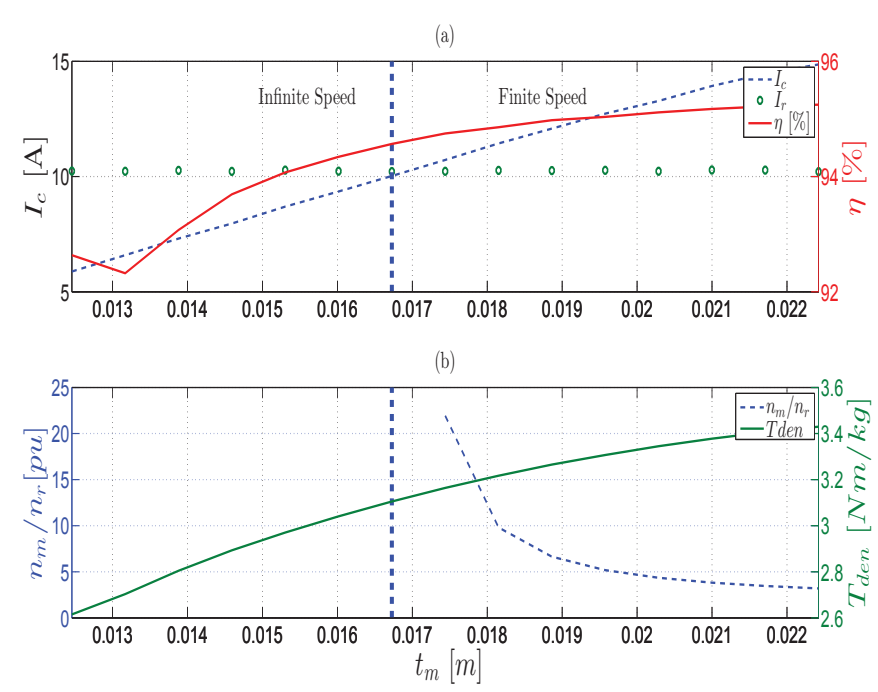

Fig. 7: Magnet width Impact (a) $t_{m}$ versus $I_{c}, I_{r}$, and the $\eta$ (b) $t_{m}$ versus the torque to weight ration, and the Per unit speed $\frac{n_{m}}{n_{r}}$.

\section{NUMBER OF SLOTS AND POLES COMBINATIONS IMPACT}

Figures 8 and 9 show the impact of different slots and poles combinations, described in Table II, on the efficiency, maximum speed ratio, torque density, and cogging torque.

According to the graph 8 , at each combination the machine efficiency, $I_{c}$ and $\left(\frac{n_{m}}{n_{r}}\right)$ have been calculated and shown in the bar graph. Very interesting results are shown here. Some combinations like $1,3,6,7,8,9,10$, and 12 provide promising 
capabilities for the FW. However few combinations only could achieve this with higher efficiency, combinations 1 and 3 are good examples for that. It can be concluded from the graph also that combinations with less difference between the number of slots and number of poles (i.e: 1 and 3) would provide a FW capabilities with high efficiency. This would conclude that selecting the best combination of the number of slots and poles could be a perfect choice if there is no any conflict with any other parameter. As an example Fig.9 shows a sample of such conflicts. In this figure the impact of the selected combination on the cogging torque is shown. From this figure, combination number 7 could be the optimum choice from the efficiency, $\mathrm{FW}$, and low cogging torque points of view.

I.

TABLE II: Number of slots and Poles combinations.
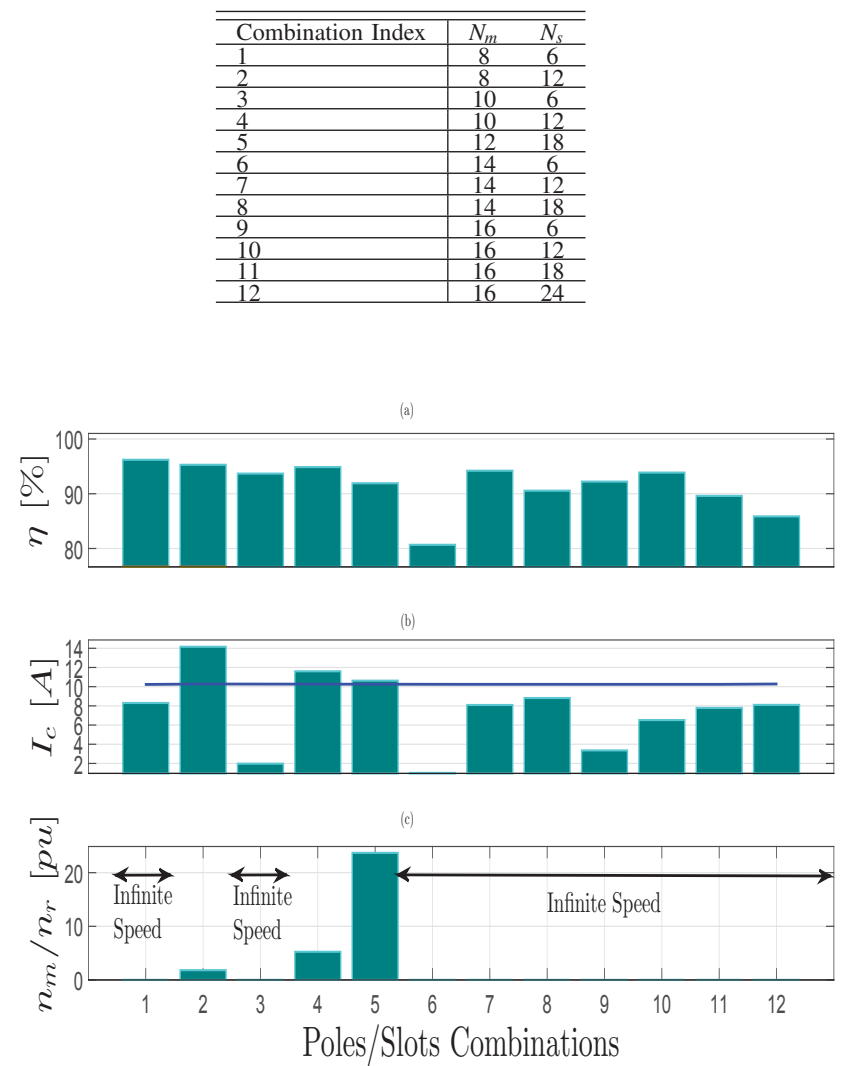

Fig. 8: $\eta, I_{c}$, and the Per unit speed $\frac{n_{m}}{n_{r}}$ versus Slots and Poles Combinations Index.

\section{MUlti-Phase IMPACT}

From Fig. 10, four different categories of the available combinations are described in Table III. These combinations could be summarized as below;

1- High efficiency with very limited CPSR, this is clearly shown in combination 1 and 4 as examples.

2- High efficiency with finite CPSR, but the maximum reachable speed is higher than the previous example, this is clearly shown in combination number 2 .

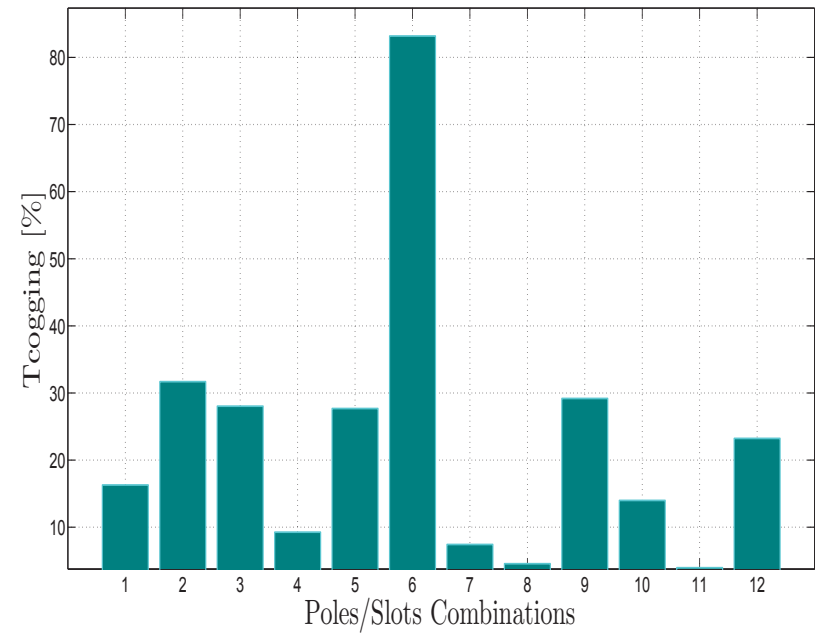

Fig. 9: cogging torque versus Slots and Poles Combinations Index.

3- Higher efficiency with infinite speed, this is shown in combinations 6 and 10 as examples.

4- Last category showing lower efficiency and limited CPSR, this is clearly shown in 5 and 11 as examples.

From Fig. 11, the impact on the cogging torque at each combination is quite clear as well.

I.

TABLE III: Number of slots and Poles combination.

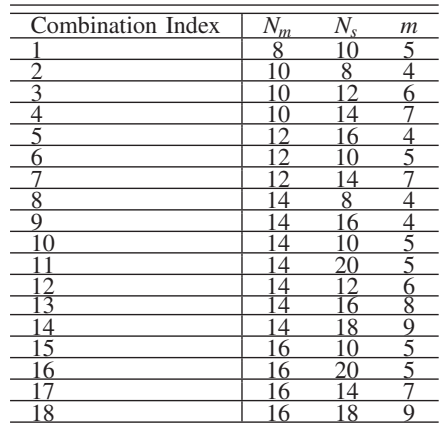

\section{CONCLUSiOn}

In conclusions, The analysis shown in this paper could be used during the design phase of the axial flux machine for high speed applications. The analysis shows a group of key design parameters that could be utilized to enhance the field weakening capability of the axial flux machine keeping the rated machine efficiency and torque density high as much as possible. The impact of the design parameters on the overall characteristic current (flux linkage and the inductance) has been discussed rather than the impact on the machine inductance only. This concept has widen the design scope rather than considering the change in the machine inductance only. It has been shown that the dominant parameters affecting the 
(a)
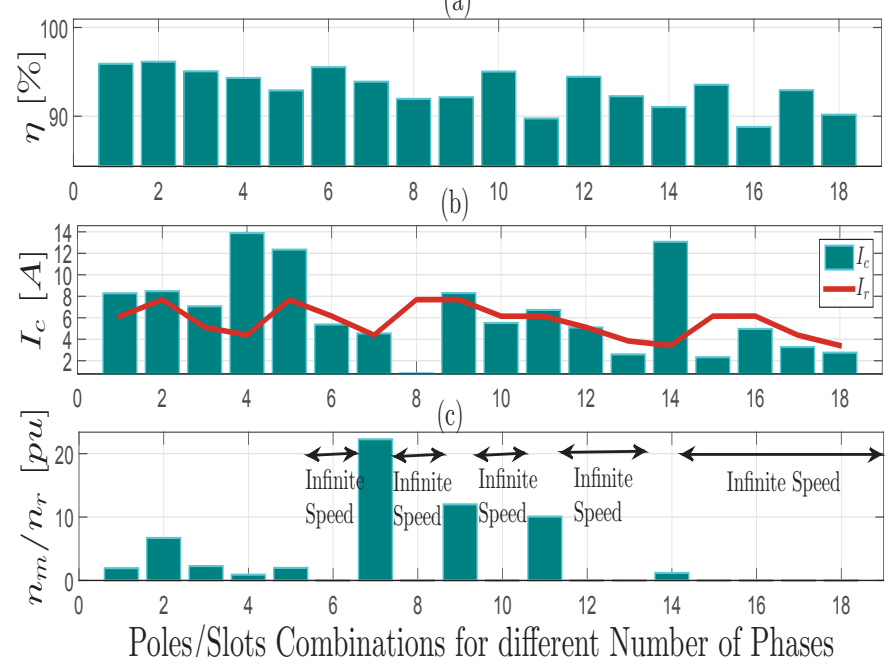

Fig. 10: $\eta, I_{c}$, and the Per unit speed $\frac{n_{m}}{n_{r}}$ versus Multi phase combinations index.

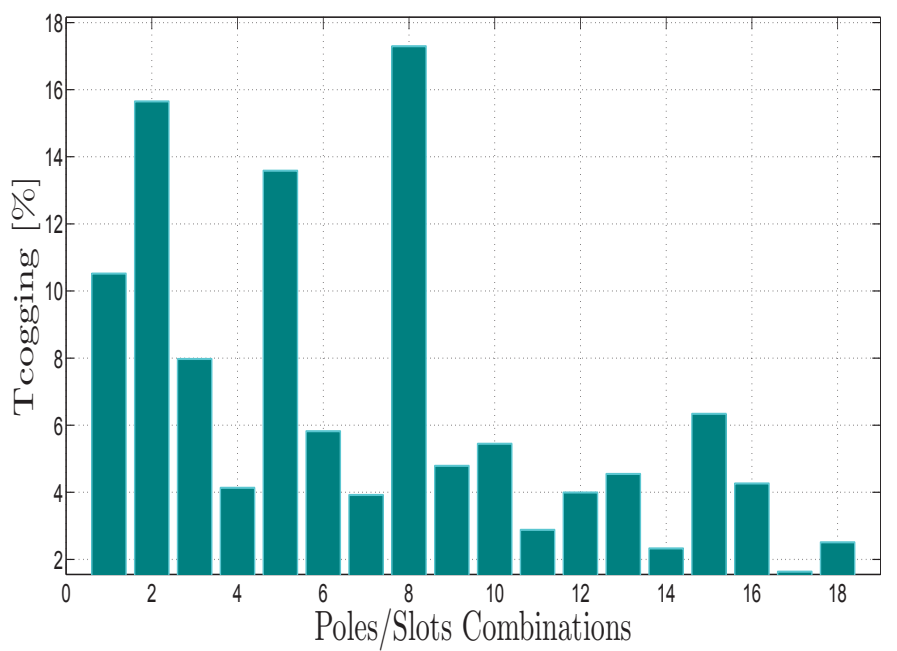

Fig. 11: cogging torque versus Multi phase combinations index.

design constraints are slots and poles combinations, number of phases, and slot opening. It can be concluded from the proposed study that considering a high speed operation range could be achieved by selecting the proper value of a certain parameter based on the design curves taking into account the other machine constrains like the machine efficiency and the torque density.

\section{ACKNOWLEDGMENT}

This work is supported by FWO project G.0110.13. and the Egyptian cultural and mission affairs.

\section{REFERENCES}

[1] D.Patterson and R. Spke, "Development of an Axial Flux Permanent Magnet Brushless DC Motor for Wheel Drive in a Solar Powered Vehicle,” IEEE Trans. Ind. App., Vol 31, no. 5, Sep, 1995.
[2] B.J. Chalmers, E. Spooner, and W. Wu, "An axial flux permanent magnet generator for a gearless wind energy system," IEEE Transactions on Energy Conversion, Vol. 14, no. 2, June 1999.

[3] F. Giulii Capponi, G. De Donato and F. Caricchi, "Recent Advances in Axial-Flux Permanent-Magnet Machine Technology," IEEE Trans. Ind. Appl., vol. 48, no. 6, pp. 2190 - 2205, 2012. [3] M.

[4] Aydin, S. Huang and T. Lipo, "Axial Flux Permanent Magnet Disc Machines: A Review," in SPEEDAM, Capri, Italy, May 2004.

[5] DU-BAR, "Design of an axial flux machine for an in-wheel motor application," PhD dissertation, Chalmers University OF Technology, Sweeden, 2011.

[6] T. F. Chan, and L. L. Lai "An Axial-Flux Permanent-Magnet Synchronous Generator for a Direct-Coupled Wind-Turbine System", IEEE Trans. on energy conversion, vol. 22, no. 1, March 2007.

[7] T. Kwon,S. Sul, L. Alberti, and N. Bianchi, "Design and control of an axial-flux machine for a wide flux-weakening operation region,'IEEE Ttrans Ind. Appl., Vol. 45, no. 4, JULY 2009.

[8] A.M. EL-Refaie, and Thomas M. Jahns, "Optimal Flux Weakening in Surface PM Machines Using Fractional-Slot Concentrated Windings," IEEE Trans. Ind. Appl., vol. 41, no. 3, May 2005.

[9] A.M. EL-Refaie, Thomas M. Jahns, Patrick J. McCleer, , and John W. McKeever, "Experimental Verification of Optimal Flux Weakening in Surface PM Machines Using Concentrated Windings," IEEE Trans. Ind. Appl., VOL. 42, NO. 2, March 2006.

[10] W. Soong and T. Miller, "Field weakening performance of brushless synchronous ac motor drives," IEE Proc. Electr. Power Appl., 1994.

[11] M. Aydin, S. Huang, and T. Lipo, "Axial Flux Permanent Magnet Disc Machines: A Review,'in International Symposium on Power Electronics, Electrical Drives, Automation and Motion (SPEEDAM), pp. 61-71, Capri, Italy, May 2004.

[12] F. Giulii, G. De Donato, and F. Caricchi, "Recent Advances in Axial Flux Permanent Magnet Machine Technology," IEEE Trans. Ind. Appl., vol. 48, no. 6, pp. 2190 - 2205, Nov. 2012.

[13] R. Schiferl and T. A. Lipo, "Power capability of salient pole P.M. synchronous motors in variable speed drive," in Conf. Rec. IEEE IAS Annu. Meeting, 1988, pp. 2331.

[14] W. L. Soong and T. J. E. Miller, "Theoretical limitations to the field weakening performance of the five classes of brushless synchronous AC motor drive," in Proc. Int. Conf. Elect. Mach. Drives, Oxford, U.K., Sep. 8 10, 1993, pp. 127132.

[15] M. Taha, O. A. Mahgoub, and S. Zaid "Simulation Study of a New Approach for Field Weakening Control of PMSM" Journal of Power Electronics (JPE), vol.12, no.1, pp.136-144, 2012.

[16] A. Hemeida and P. Sergeant, "Analytical Modeling of Surface PMSM Using a Combined Solution of Maxwell's Equations and Magnetic Equivalent Circuit (MEC)," IEEE Trans. Magn., vol. 50, no. 12, Art. No. 7027913, June. 2014.

[17] A.Hemeida and P. Sergeant, "Analytical Modeling of Eddy Current Losses in Axial Flux PMSM Using Resistance Network," in International Conference on Electrical Machines (ICEM), Berlin, Germany, Sept. 2014.

[18] P. Sergeant, H. Vansompel, A. Hemeida, A. Van den Bossche, and L. Dupré, "A computationally efficient method to determine iron and magnet losses in VSI-PWM fed axial flux permanent magnet synchronous machines," IEEE Trans. Magn., vol. 50, no. 8, Art. No. 8101710, Feb. 2014.

[19] D. Zarko, D. Ban, and T. Lipo, "Analytical calculation of magnetic field distribution in the slotted air gap of a surface permanent-magnet motor using complex relative air-gap permeance," IEEE Trans. Magn., vol. 42, no. 7, pp. 1828-1837, 2006.

[20] A. EL-Refaie, "Fractional-Slot Concentrated-Windings Synchronous Permanent Magnet Machines: Opportunities and Challenges," IEEE Trans. Ind. Electron., vol. 57, no. 1, pp. 107 - 121, 2010.

[21] A.M. EL-Refaie, M.R. Shah, Qu Ronghai, J.M. Kern, "Effect of Number of Phases on Losses in Conducting Sleeves of Surface PM Machine 
Rotors Equipped With Fractional-Slot Concentrated Windings," IEEE Trans. Ind. Appl., vol.44, no.5, pp.1522-1532, Sept.-Oct. 2008

[22] S. Huang, M. Aydin, and T. A. Lipo, "A direct approach to electrical machine performance evaluation: torque density assessment and sizing optimization," Proc. Int. Con. Elec. Machines, (ICEM'02), Belgium, August 25- 28, 2002.

\section{BIOGRAPHIES}

Ahmed Hemeida was born in Egypt in 1987. He received B.Sc. M.Sc degrees in electrical power and machines engineering from Cairo University, Egypt, in 2009 and 2012 respectively. He is currently working towards his Ph.D. degree starting from 2013 at the Department of Electrical Energy, Systems and Automation, Ghent University. His current research interests include electrical machines modeling and design, particularly for sustainable energy systems.

Mohamed Taha Elsayed was born in Egypt in 1980. He received the B.Sc. M.Sc and, Ph.D. degrees in electrical power and machines engineering from Cairo University, Giza, Egypt, in 2002 ,2006 and 2012, respectively. Since 2012, he is working as a lecturer at the Cairo University, Giza, Egypt. He is currently a Postdoctoral Researcher at Ghent University, Belgium. He has a wide industrial experience as he has worked as a technical project manger with Schneider electric. His current research interests include machine design, machine drives and power electronics.

Peter Sergeant received the M.Sc. degree in electromechanical engineering in 2001, and the Ph.D. degree in engineering sciences in 2006, both from Ghent University, Ghent, Belgium. In 2001, he became a researcher at the Electrical Energy Laboratory of Ghent University. He became a postdoctoral researcher at Ghent University in 2006 (postdoctoral fellow of the Research Foundation - Flanders) and at Ghent University College in 2008. Since 2012, he is associate professor at Ghent University. His current research interests include numerical methods in combination with optimization techniques to design nonlinear electromagnetic systems, in particular, electrical machines for sustainable energy applications 